\title{
Pseudoangiomatous squamous cell carcinoma: a challenge for pathologists and plastic surgeons
}

\section{Dimitrios Kanakopoulos ${ }^{1}$, Evgenios Evgeniou², Panayiotis A. Dimitriadis ${ }^{3}$, Mahendra Kulkarni ${ }^{4}$}

${ }^{1}$ Department of Plastic Surgery, Southmead Hospital, Bristol, BS105NB, UK.

${ }^{2}$ Department of Plastic Surgery, Derriford Hospital, Plymouth, PL68DH, UK.

${ }^{3}$ Department of ENT, Lister Hospital, Stevenage, SG14AB, UK.

${ }^{4}$ Department of Plastic Surgery, Wexham Park Hospital, Slough, SL24HL, UK.

Address for correspondence: Mr. Evgenios Evgeniou, 43 Friars Place Lane, East Acton, London, W3 7AQ, UK.

E-mail: evgenios@doctors.org.uk

\begin{abstract}
Pseudo-angiosarcomatous or pseudovascular squamous cell carcinoma (SCC) of the skin is an unusual variant form of acantholytic SCC that mimics the histopathological appearance of angiosarcoma. We describe a case of pseudovascular SCC in a 77-year-old lady to highlight the frequent recurrence and aggressiveness, as well as the clinicopathological features of this rare form of cutaneous SCC, and demonstrate the difficulties in establishing the correct diagnosis. Plastic surgeons involved in the care of patients with cutaneous malignancies should be aware of this variant of SCC and its aggressive nature in order to manage these patients appropriately.
\end{abstract}

Key words:

Carcinoma, pseudosarcoma, squamous, squamous cell carcinoma

\section{INTRODUCTION}

Squamous cell carcinoma (SCC) is a nonmelanoma skin cancer and the second most common type of skin cancer. $^{[1]}$ These cases most commonly arise in sun-exposed skin areas in middle-aged or elderly patients. ${ }^{[2]}$ The classic presentation for a cutaneous SCC is a shallow ulcer with heaped-up edges, often covered by plaque, usually in a sun-exposed area. Typical surface changes may include a smooth or hyperkeratotic enlarged plaque, nodule, ulceration, crusting, or cutaneous horn. ${ }^{[1]}$ Histologically, there is a characteristic proliferation of atypical keratinocytes that invade the dermis, with areas of detachment from the overlying epidermis. These anastomosing growths of cords and nests are composed

\begin{tabular}{|l|l|}
\multicolumn{2}{|c|}{ Access this article online } \\
\hline Quick Response Code: & Website: \\
\hline & www.parjournal.net \\
\hline & \\
\hline
\end{tabular}

of cells that have a glassy eosinophilic cytoplasm and enlarged nuclei. Mitotic figures, keratin pearls, and dyskeratotic keratinocytes are variably present. ${ }^{[3]}$ Pseudo-angiosarcomatous or pseudovascular SCC of the skin is an unusual and highly aggressive variant form of SCC. ${ }^{[4]}$

\section{CASE REPORT}

A 77-year-old lady was referred to plastic surgery from dermatology with a biopsy that confirmed the presence of a poorly differentiated acantholytic SCC. On examination, she had an exophytic growth on the anterior aspect of the lower third of her left leg, with multiple satellite lesions and associated edema. There was no palpable lymphadenopathy or organomegaly present. An X-ray assessment of her left leg was performed, showing no bony involvement. A wide local excision of the lesion with a $1 \mathrm{~cm}$ peripheral margin down to the fascia was performed, and the wound was resurfaced with a split-thickness skin graft. Although histology confirmed that the tumor had been completely excised with an adequate margin and the wound had healed nicely within 3 weeks, the patient presented at 6 weeks with 
exophytic lesions at the edge of the skin grafted area [Figure 1]. The clinical appearance was consistent with an early recurrence. The patient underwent an urgent re-excision with $1 \mathrm{~cm}$ margins followed by split-thickness skin grafting. Histology confirmed a poorly differentiated SCC with marked acantholysis and pseudovascular spaces lined with atypical cells [Figures 2 and 3]. The differential diagnosis was that of a poorly differentiated pseudo-angiosarcomatous SCC or true angiosarcoma with prominent epithelioid cell morphology. Immunohistochemistry showed the tumor cells to be negative for the endothelial/vascularmarkers, erythroblast transformation specific related gene and cluster of differentiation 31, and for desmin and carcinoembryonic antigen. It was concluded that the tumor was a poorly differentiated acantholytic pseudo-angiosarcomatous SCC. Due to the narrow deep excision margin and the aggressiveness of the tumor, further excision was offered to the patient but this was refused. Less than 4 weeks from the second wide/local excision, the patient presented with a new erythematous lesion at the site of the original excision, which on histologic assessment indicated a further recurrence. Complete resection of the tumor was achieved. Several weeks postsurgery, the patient underwent radiotherapy to target any residual tumor cells and prevent further recurrence. A staging computed tomography evaluation did not reveal evidence of distant metastasis. After completion of the radiotherapy course and 6 months after her last operation she was evaluated by plastic surgery and found to be well with no local or regional recurrence and no lymphadenopathy.

\section{DISCUSSION}

Pseudo-angiosarcomatous or pseudovascular SCC of the skin is an unusual variant form of acantholytic (adenoid, pseudoglandular) SCC that mimics the histopathologic appearance of angiosarcoma. ${ }^{[5]}$ It is a relatively rare malignancy with only 19 cases described in the English literature..$^{[4]}$ It is characterized by a pseudoglandular pattern in the histological study, and although the tumor has the clinical characteristics of SCC, histologically it may mimic an angiosarcoma. ${ }^{[4,5]}$ However, careful histological examination and immunohistochemical study can usually lead to the correct diagnosis. Acantholytic foci in these tumors may demonstrate changes in keratinocyte differentiation markers, and this may explain more aggressive biological behavior in the pseudovascular variant of SCC. ${ }^{[6]}$ Pseudovascular SCC share a poorer prognosis as they demonstrate a higher degree of recurrence and metastasis than other variants of SCC. [7] Due to the possibility of early recurrence in these patients, plastic surgeons should consider evaluating patients with pseudovascular SCC more frequently than patients with other clinical subtypes of SCC.

Although there have not been specific studies regarding the role of adjuvant treatment in the management of

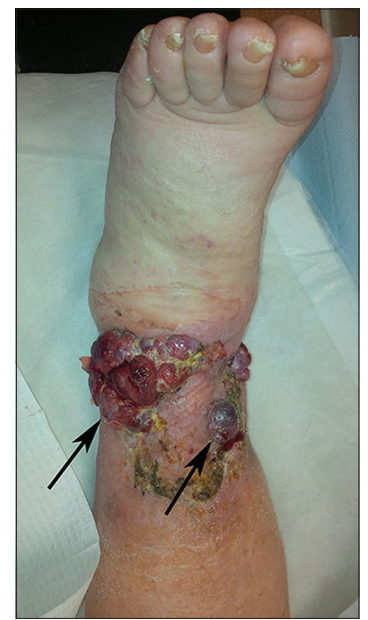

Figure 1: Recurrence of squamous cell carcinoma presenting as exophytic lesions (arrows) at the edge of the skin grafted area

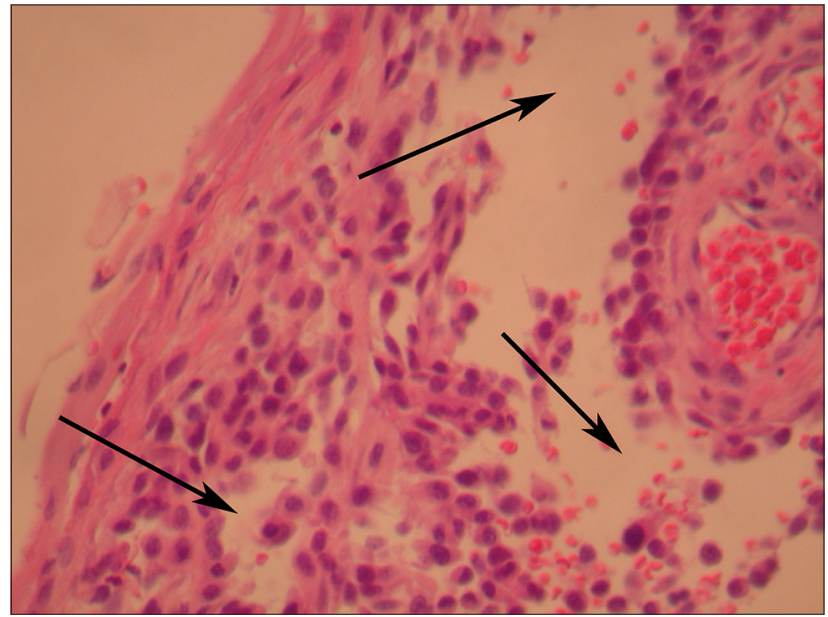

Figure 2: Histopathological specimen showing acantholysis with overlying epidermis (arrows)

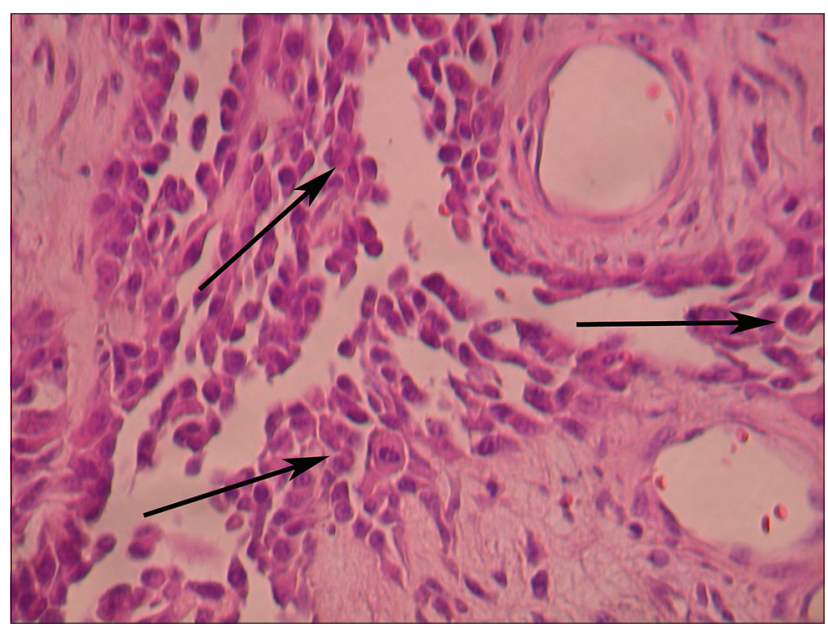

Figure 3: Histopathological specimen showing a pseudovascular space lined by tumor cells (arrows) and adjacent normal blood vessels

psudovascular SCC, adjuvant radiotherapy has been recommended for cases of SCC with a high risk of recurrence, particularly perineurally invasive disease. ${ }^{[8]}$ The role of systemic chemotherapy and isolated limb perfusion in cutaneous SCC remains uncertain. ${ }^{|9,10|}$ 


\section{REFERENCES}

I. Lansbury L, Bath-Hextall F,Perkins W, Stanton W, Leonardi-Bee J. Interventions for non-metastatic squamous cell carcinoma of the skin: systematic review and pooled analysis of observational studies. BMJ 20I3;347:f6I 53.

2. Kivisaari A, Kähäri VM. Squamous cell carcinoma of the skin: emerging need for novel biomarkers. World J Clin Oncol 20।3;4:85-90.

3. Edge S, Byrd D, Compton C. Cutaneous squamous cell carcinoma and other cutaneous carcinomas. In: AJCC Cancer Staging Manual. 7th ed. New York: Springer; 2009. p. $30 \mathrm{I}-9$.

4. Koh SH, Oh SJ, Chun H, Kim SG. Pseudoangiosarcomatous squamous cell carcinoma developing on a burn scar: a case report and review of the literature. Burns 2014;40:e47-52.

5. Conde-Taboada A, Flórez A, De la Torre C, Feal C, García-Doval I, Cruces M. Pseudoangiosarcomatous squamous cell carcinoma of skin arising adjacent to decubitus ulcers. Am J Dermatopathol 2005;27:142-4.

6. Nappi O,Wick MR, Pettinato G, Ghiselli RW, Swanson PE. Pseudovascular adenoid squamous cell carcinoma of the skin. A neoplasm that may be mistaken for angiosarcoma. Am J Surg Pathol 1992; 16:429-38.

7. Nagore E, Sánchez-Motilla JM, Pérez-Vallés A, Martínez-Lahuerta C,AlegreV,
Aliaga A. Pseudovascular squamous cell carcinoma of the skin. Clin Exp Dermatol 2000;25:206-8.

8. Jambusaria-Pahlajani A, Miller CJ, Quon H, Smith N, Klein RQ, Schmults CD. Surgical monotherapy versus surgery plus adjuvant radiotherapy in high-risk cutaneous squamous cell carcinoma: a systematic review of outcomes. Dermatol Surg 2009;35:574-85.

9. DeConti RC. Chemotherapy of squamous cell carcinoma of the skin. Semin Oncol 2012;39: I45-9.

10. Turaga KK, Beasley GM, Kane JM 3rd, Delman KA, Grobmyer SR, Gonzalez RJ, Letson GD, Cheong D, Tyler DS, Zager JS. Limb preservation with isolated limb infusion for locally advanced nonmelanoma cutaneous and soft-tissue malignant neoplasms. Arch Surg 201 I; I 46:870-5.

How to cite this article: Kanakopoulos D, Evgeniou E, Dimitriadis PA, Kulkarni M. Pseudoangiomatous squamous cell carcinoma: a challenge for pathologists and plastic surgeons. Plast Aesthet Res 2015;2:88-90.

Source of Support: Nil, Conflict of Interest: None declared.

Received: 09-10-2014; Accepted: 13-11-2014 